\title{
REFLEXOES SOBRE O COMPORTAMENTO DAS ENFERMEIRAS PERANTE AS MÃES NA UNIDADE PEDIÁTRICA
}

Edelia del Pilar Neira Huerta*

NEIRA HUERTA, E. del P. Reflexðes sobre o comportamento das enfermeiras perante as măes na unidade pediátrica. Rev. Esc. Enf. USP, São Paulo, 18(3):209-214,1984.

Através de algumas reflexões em relação aos motivos que provocamo comportamento que as enfermeiras apresentam ante a presença das mäes na unidade pediátricas, a autora mostra seu modo de compreendê-las.

Durante minhas vivências em unidades pediátricas - como aluna, como enfermeira de campo e como mãe - pude observar que as enfermeiras interagiam escassamente e de maneira pouco efetiva com as mães que visitavam ou acompanhavam seus filhos no hospital; conseqüentemente, não estabeleciam com elas relacionamento profundo e de confiança que, como resultado da experiência de hospitalização da criança, permitisse a ambas - enfermeira e mae - desenvolver-se pessoal e profissionalmente.

Mais tarde, como docente, acompanhando alunos em seu aprendizado de enfermagem pediátrica, em um hospital governamental, cuja filosofia valoriza o cuidado integral à criança, comprovei, com espanto, que o comportamento das enfermeiras desta instituição, era o mesmo que eu observara em minhas experiências anteriores e que EU definira como de indiferença.

Inicialmente, interpretei este comportamento como sendo resultado de desinteresse, negligência ou acomodação à burocracia hospitalar.

Posteriormente, durante uma conversa informal, a enfermeira A. me disse: "É muito difícil ficar perto dos pais de uma criança grave ou em fase terminal de doença ... a gente se apega à criança e acaba por se envolver com os pais dela ... só consigo chorar perto deles. É bom saber que sou capaz de sentir, mas acho que essa atitude não ajuda os pais e não é nada profissional.

- Enfermeira. Mestre em enfermagem. Professor Assistente do Departamento de Enfermagem Materno - Infantil e Psiquátrica da Escola de Enfermagem da USP - disciplina Enfermagem Pediátrica. 
A enfermeira não deve expressar seus sentimentos ... aqui no hospital a gente é uma coisa e lá fora é diferente... a nossa família não entende porque a gente sempre está contando as coisas que acontecem no hospital".

A enfermeira E., no decorrer de uma entrevista, à qual ela respondia calmamente e muito à vontade, bruscamente mudou sua postura corporal e seus olhos encheram-se de lágrimas ao confidenciar-me: “. .. quando comecei a trabalhar como enfermeira, faz quase sete anos, nesta mesma unidade, eu sofria muito vendo o sofrimento das crianças; sofria mais ainda quando uma delas falecia... eu me envolvia demais ... cansei de levar meu sofrimento para casa, não era justo; decidi me afastar das crianças para parar de sofrer".

Refleti muito sobre o conteúdo e o significado de suas verbalizaçð̌es; ambas percebem e reconhecem o sofrimento nas crianças, como, também, seus próprios sentimentos, mas não sabem lidar com eles. A primeira enfermeira mencionada, percebe também o sofrimento dos pais, mas não sabe o que fazer para ajudá-los; ela acredita que chorar, além de ser "uma atitude não profissional", não ajuda os pais.

Finalmente, compreendo que eu estava errada: estas enfermeiras não são indiferentes à presença das mães na unidade pediátrica; elas apenas usam uma máscara porque não sabem lidar com os sentimentos e dificuldades que a presença das mães e das crianças doentes provocam e representam para elas. Agora sei que elas fogem, escondendo-se por trás de uma fachada de indiferença.

Mc CARTHY ${ }^{5}$ afirma que a indiferença é apenas uma reação a não saber lidar com os problemas e dificuldades.

Compreendo também que essas enfermeiras estão sofrendo: elas sentem de um modo, porém se comportam de outro, conseqüentemente elas sofrem constante ansiedade.

Segundo MENZIES ${ }^{6}$, o uso de mecanismos de defesa inibe o pleno desenvolvimento das capacidades que permitem ao invididuo lidar com a realidade e dominar a ansiedade e, deste modo, ele se sente desamparado diante de tarefas, situações ou problemas novos ou estranhos.

- Por que elas não se permitem ser autênticas?

- Por que elas não procuram colegas ou outros profissionais de equipe de: saúde para expressar seus sentimentos e falar de suas dificuldades e problemas?

Acredito que não o fazem porque lesariam a imagem profissional que, segundo elas, devem mostrar; porque acreditam que se o fizessem não atende- 
riam às expectativas de seus colegas e de outros profissionais da equipe hospitalar a seu respeito.

EPSTEIN $^{1}$ opina que as enfermeiras geralmente estão empenhadas em apresentar a seus clientes e colegas da equipe de saude uma fachada unidimensional, congruente com o esterebtipo de enfermeira, sendo que, segundo a autora, esta atitude é chamada de profissional.

Não posso deixar de me perguntar: e os outros profissionais da equipe hospitalar, particularmente os outros enfermeiros, com maior experiência de campo, que provavelmente já experimentaram e, quem sabe, continuam a experimentar sentimentos e dificuldades similares, não se interessam pelos colegas que começam a exercer a profissão? Não percebem seu comportamento? Será que nenhum deles lhes demonstra interesse e disponibilidade para compreendê-los e ajudá-los? Será que eles tampouco se permitem ser autênticos? Será que eles também não procuram outros membros da equipe de saúde para falar sobre seus sentimentos e dificuldades e, conseqüentemente, também precisam utilizar mecanismos de defesa contra a ansiedade?

MENZIES ${ }^{6}$ declara: "a falta de apoio ao indivíduo nos relacionamentos de trabalho, em todo serviço de enfermagem, é notável; estes serviços se caracterizam por um grande isolamento de seus membros; cada um executa seus deveres e existe percepção mínima dos colegas".

Esta mesma autora, que estudou a ansiedade crônica das enfermeiras, explica que os serviços de enfermagem utilizam mecanismos de defesa socialmente estruturados para conter e modificar a intensa ansiedade que, pela própria natureza da profissão e pelas características ansiogênicas da situação de trabalho, as invade. A autora enfatiza que estes mecanismos privam as enfermeiras de segurança e satisfação profissional, gerando profunda ansiedade secundária.

Pergunto-me: não será este fato um dos motivos que afasta, cada dia mais, o enfermeiro de seus clientes?

Sabemos que os enfermeiros, para justificar este afastamento, esta omissão em relação a seus clientes, se agarram às pressð̃es da instituição para a qual trabalham. Isto, segundo MENZIES $^{6}$, deve ser visto como resistência a mudanças, explicando que estas ameaçam as defesas existentes e geram ansiedade mais profunda e mais intensa; conseqüentemente, a fim de fugir dessa ansiedade, os serviços de enfermagem tentam resistir, na medida do possível, as mudanças.

Como ajudar estas enfermeiras a se libertarem desta ansiedade, para que possam ter uma vida plena como profissionais e como pessoas? De quem é esse compromisso? 
Sabemos que estas enfermeiras trabalham para uma instituição cuja filosofia valoriza a assistência integral à criança e, conseqüentemente, a considera como um ser integral, que tem sentimentos e que necessita sentir-se amada e que pertence a seus pais e a uma família. Não deveria esta instituição zelar pelo preparo de seu pessoal, especialmente o profissional, de maneira a desenvolver neles atitudes que lhes permitam comportar-se de forma condizente com essa filosofia? que lhes permitam ser autênticas, e portanto mais efetivas?

Segundo KING* as atitudes da equipe hospitalar refletem mais a organização da instituição do que as características pessoais de cada um de seus membros.

FAGIN \& NUSBAUM ${ }^{3}$ afirmam que as atitudes da equipe hospitalar podem ser mudadas através de educação em serviço.

HARDGROVE \& KERMOIAN ${ }^{4}$, no seu estudo sobre políticas e práticas em unidades pediátricas que incluem os pais, concluem que existe uma forte necessidade de educação dos profissionais de saúde em relação aos problemas da criança hospitalizada e sua familia, afirmando ser responsabilidade da instituição prover recursos e atitudes para assim promover o bem-estar da criança e de seus pais.

Nos recursos que estes autores mencionam, eu incluo a promoção de reuniðes periódicas da equipe hospitalar, com o propósito de que cada membro possa discutir, numa atmosfera de abertura, não avaliadora e de contribuiçôes mútuas, seus problemas e dificuldades, tentando constantemente definir a natureza destes. Seria esta, para mim, uma medida oportuna e necessária para falar sobre experiências pessoais, de recordar as emoçðes sentidas e, portanto, uma oportunidade para lidar com elas, diminuir ansiedade e de se permitir ser o que realmente se é.

Como educadora me pergunto:

- Por que estas enfermeiras não aprenderam a lidar com seus próprios sentimentos e dificuldades? Não deveria ser esse um dos principais efeitos do processo educativo?

- Por que elas precisam sofrer para não demonstrar "atitudes não profissionais"?, quando na verdade não sendo autênticas elas NÃO SÃO enfermeiras e, conseqüentemente, não são profissionais realizadas na profissão que escolheram, nem darão assistência realmente efetiva a seus clientes.

EPSTEIN $^{1}$ opina que os educadores devem-se questionar em relação aos efeitos na aprendizagem e no comportamento, quando impбem cursos tradi-

* apud STEWART \& MAC GREGOR ${ }^{7}$ 
cionais, ignorando os problemas dos alunos. Esta mesma autora é enfática ao afirmar que enquanto os futuros integrantes de uma profissão forem educados em situações e métodos que encorajam a rigidez e, enquanto ignorarem o ensino de relaçðes humanas, eles continuarão a sofrer frustaçðes e ansiedade.

Segundo MENZIES ${ }^{6}$ o sistema de educação em enfermagem é principalmente orientado para a comunicação de fatos e técnicas essenciais, conferindo mínima atenção ao ensino de eventos orientados para a maturação pessoal na área profissional, não existindo portanto, aprendizagem orientada para ajudar os estudantes de enfermagem a elaborar o impacto de suas primeiras tentativas na prática de enfermagem e lidar com mais eficácia em suas relações emocionais, resultando daí ansiedade contida, que por sua vez inibe um trabalho de elaboração posterior no seu exercício profissional que leve à mudança.

Como educadora me pergunto: será que estamos oferecendo a nossos alunos oportunidade para enfrentarem e trabalharem com suas reaçбes emocionais? Será que os ajudamos a se libertarem de ansiedade? Será que os ajudamos a se tornarem enfermeiros?

CLEMENCE* afirma: "a enfermeira não comprometida permanecerá afastada dos problemas de seus pacientes porque estes the provocam sofrimento. Em termos existencialistas, ela não é uma enfermeira... ela simplesmente desempanha funções de uma enfermeira".

Segundo EYRES ${ }^{2}$ enfermeiro comprometido é aquele que possui uma filosofia de vida e de prática profissional com as quais ele se sente e está comprometido; é aquele que é capaz de se envolver e de utilizar terapeuticamente a si próprio.

Mas, como tornar-se uma enfermeira? A este respeito EYRES ${ }^{2}$ declara: "Quanto mais você, como pessoa, tiver vivências dentro das enfermarias e na vida privada, maior progresso você fará em direção à verdadeira enfermagem; quanto mais você viver e aprender sobre si próprio, tanto mais você avançará na verdadeira prática de enfermagem".

Proporcionamos a nossos alunos experiências que lhes permitam sentir e aprender sobre si próprios? Oferecemos a eles experiências que lhes permitam tornar-se enfermeiros? Ajudamos nossos alunos e colegas de campo a se libertarem de ansiedade para que possam ter uma vida plena como profissionais e como pessoas?

Reconheço como compromisso do educador de enfermagem ajudar seus

* apud EYRES ${ }^{2}$ 
alunos e seus colegas de campo a serem aquilo que eles realmente são e aquilo que eles podem vir a ser na profissão que escolheram.

Somos profissionais comprometidos, capazes de nos envolver com nossos alunos e colegas de campos? Estamos assumindo esse compromisso?

NEIRA HUERTA, E. del P. Mothers in the pediatric ward: an analysis of the nurse's behavior. Rev. Esc. Enf. USP, São Paulo, 18(3): 209-214, 1984.

The author noticed an indifferent attitude on the part of nurses in the presence of mothers in the pediatric ward and reflects upon what she understands to be possible reasons for this behavior.

\section{REFEREANCIAS BIBLIOGRÁFICAS}

1. EPSTEIN, C. Interaço efetiva na enfermagem. São Paulo, E.P.U., 1977.173 p.

2. EYRES, P. The role of the nurse in the family - centered nursing. Nurs. Clin. North Amer., Philadelphia, 7(1):27-39, Mar. 1972.

3. FAGIN, C. M. \& NUSBAUM, J. G. Parental visiting privileges in pediatric units: a survey. J. Nurs. Adm., Billerica, 8(3):24-27, Mar. 1978.

4. HARDGROVE, C. \& KERMOIAN, R. Parent - inclusive pediatric units: a survey of policies and practices. Amer. J. Publ. Health, New York, 68(9):847-50, Sept. 1978.

5. Mc CARTHY, D. The under fives in hospital. Nurs. Times, London, 77(30; suppl.) :22-8, July, 1981 .

6. MENZIES, I. E. P. El funcionamento de los sistemas sociales $\infty$ mo defensa contra la ansiedad. In: \& JAQUES, E. Los sistemas sociales como defensa contra la ansiedad. 2.ed. Buenos Aires, Hormé, 1974.122 p.

7. STEWART, M. E. \& Mc GREGOR, S. M. The experiencies of young children in a kingston hospital, Jamaica, West. Indian Med. J., Kingston, 28(1):30-5, 1979. 